\title{
LA CONSTITUCIONALIZACIÓN DEL PROCESO
}

\section{THE CONSTITUTIONALIZATION OF THE PROCESS}

Antonio María Lorca NavarreteCatedrático de Derecho Procesal Penal

Universidad del País Vasco alorca@ehu.eus

España

\section{SUMARIO}

- El itinerario a seguir en las relaciones entre proceso y constitución

- El logro de una convivencia en paz

- El «método» relativo a la finalidad que persigue el Derecho Procesal con la mirada puesta en el único referente que lo legitimaría como es el texto constitucional

- La «responsabilidad» del Derecho Procesal

- El compromiso constitucional del Derecho Procesal

- La sustantividad del Derecho Procesal

- El «concepto de justicia» que propugna el Derecho Procesal

- La «justicia o verdad» que garantiza el Derecho Procesal

- Conclusiones

\section{RESUMEN}

Este artículo busca dar a conocer el itinerario a seguir en las relaciones entre proceso y Constitución. Se precisa cuál es el método relativo a la finalidad que persigue el Derecho Procesal con la mirada puesta en el único referente que lo legitimaría como es el texto constitucional. También detalla la responsabilidad del Derecho Procesal y su compromiso constitucional. Finalmente, describe la sustantividad del Derecho Procesal $\mathrm{y}$ el concepto de justicia que propugna.

\begin{abstract}
The present article seeks to present the itinerary to follow in the relations between process and constitution. It is specified what is the method relative to the purpose pursued by procedural law with a view to the only reference that would legitimize it as the constitutional text. It also details the responsibility of procedural law and its constitutional commitment. Finally, it describes the substantivity of procedural law and the concept that advocates justice.
\end{abstract}

\section{PALABRAS CLAVE}

Constitucionalización, proceso, Derecho Procesal, Derecho

\section{KEYWORDS}

Constitutionalisation, process, procedural law, right

\section{EL ITINERARIO A SEGUIR EN LAS RELACIONES ENTRE PROCESO Y CONSTITUCIÓN}

No voy a surcar las procelosas aguas de la epistemología jurídica en pos de la justicia y la verdad porque simplemente la verdad y la justicia no existen. Pero consciente de que en el anterior aserto se contiene una afirmación de calado, me esmeraré en explicarlo en las líneas que siguen a esta.

Por lo pronto, no es posible desconocer que la justicia y/o la verdad es un tema en el que se

1 Consulte la página web www.sc.ehu.es/leyprocesal 
reproducen con increíble monotonía todos los argumentos que pululan en torno a una más englobante (y ya fatigante) quaestio disputata - la de la finalidad misma del Derecho en una sociedad que se autoproclama respetuosa con el estado de Derecho- y que no sorprende a nadie por ser un tema extremadamente recurrente no solo en las explicaciones al uso en las aulas universitarias en las que se enseña Derecho cuanto también en el discurrir diario de muchos ciudadanos que en alguna ocasión de su vida han tenido que vérselas con la aplicación del Derecho.

No poca culpa de ello cabe achacar al deseo de entronizar la justicia y/o la verdad que, a modo de bálsamo de fierabrás, explicaría todo lo que gira en torno a los menesteres propios del derecho en una sociedad que se autoproclama respetuosa con el estado de derecho. Pero, esta percepción tan apacible y placentera, posee no pocos agujeros por donde desagua cualquier deseo de encumbramiento de la justicia y/o la verdad.

Así que para paliar el vértigo que inevitablemente provoca la mención a tan ajado asunto, me propongo abordarlo a través de - para mí- un atractivo argumento justificado en las relaciones entre proceso - entendido como el conjunto de actos y trámites seguidos ante un juez o tribunal, tendentes a dilucidar una "contienda judicial» (artículo 248.1. de la Ley de Enjuiciamiento Civil; o, Código Procesal Civil español) - y el texto constitucional español y ya convertido en tesis que ha comenzado a transitar en el mismísimo orbe de la teoría y práctica en orden a la resolución de la evocada "contienda judicial».

$\mathrm{Y}$ al respecto voy a asirme, de seguido, de las indicaciones de Vallespín (2002). En efecto como se ha escrito:

«Tradicionalmente, los procesalistas no fomentaron el desarrollo progresivo de la constitucionalización de la ciencia procesal, consistente en la elevación a rango constitucional de determinados principios y derechos relacionados con la organización judicial y los criterios orientadores por los que han de regirse los procesos.

El principal precursor del análisis de este fenómeno de constitucionalización de la actividad procesal fue - se ha dichoCouture, quien siguiendo los tímidos intentos de Romano y Calamandrei, procedió a examinar el proceso como un sistema repleto de garantías con el que lograr la defensa de los derechos fundamentales. Surge asi - se sigue diciendo por Vallespin Pérez-, como bien ha señalado Lorca Navarrete, un "compromiso constitucional" del procesalista, en función del cual los códigos procesales se presentan como auténticas leyes reguladoras de la garantía de justicia que aparece consagrada en la Constitución». (p. 400)

Doy por descontado que la lectura de lo que antecede es ilustrativo del itinerario a seguir por quienes deseen encumbrar con sus tesis -doctorales, en su caso-, las relaciones entre proceso y Constitución arribando a la constitucionalización del proceso.

\section{EL LOGRO DE UNA CONVIVENCIA EN PAZ}

Pero, ¿de qué naturaleza es el nexo — si es que lo hay - entre proceso y Constitución? A primera vista, y merced a la lectura del texto constitucional español ( $\sin$ la que no se cobraría conciencia de determinadas «cosas»), sería posible acuñar como metodología de estudio, la actividad denominada "función jurisdiccional» por la que unos «órganos» llamados «jurisdiccionales» —-son los órganos jurisdiccionales, juzgados y tribunalesllevan a cabo la «función» de juzgar y hacer ejecutar lo juzgado, según las exigencias constitucionales (artículo 117.3. de la Constitución española) con el fin de hacer «frente» a los casos en que existe una patología jurídica — «contienda judicial»- en el marco del logro de una convivencia en paz.

El punto en el que se desmiga el anterior y nuevo- enfoque gira en torno a una afirmación medular, a saber: la litigación - sus actores y las normas que la hacen posible, conocidas como Derecho Procesal- antes que ciencia implica y supone una ética del comportamiento humano frente a los casos en que se suscita «contienda judicial» (artículo 248.1. de la Ley de Enjuiciamiento Civil; o, Código Procesal Civil español) con el fin de, a través de ella, alcanzar entre todos los actores afectados por la litigación una propuesta - como ha quedado dicho- de convivencia pacífica. 
Y, a tal fin, el modelo de litigación español tendría por objeto propio o método de estudio el ejercicio de la denominada "función jurisdiccional» consistente en juzgar y hacer ejecutar lo juzgado, según - siempre- las exigencias constitucionales (artículo 117.3. de la Constitución española) por lo que, a ese modelo de litigación, a la vez, que solo le justifica la norma constitucional española, es funcional por hallarse justificado en el ejercicio de la denominada «función jurisdiccional» constitucional a través del proceso por los órganos jurisdiccionales, juzgados y tribunales.

Y no por inercia sino para disipar -o hacer desvanecer - los tradicionales cometidos con los que se ha adornado - ya añejamente - el Derecho Procesal, apelaré a la conveniencia (la urgencia, más bien) de vincularlo con la norma constitucional española y al compromiso - compromiso constitucional del Derecho Procesal- que adquiere ese mismo Derecho Procesal en su cometido de llevar a cabo la «función» - por la que el Derecho Procesal sería un derecho funcional. No un derecho Jurisdiccional- de juzgar y se hacer ejecutar lo juzgado por los juzgados y tribunales, según - siempre- exigencias constitucionales (artículo 117.3. de la Constitución española), en orden a hacer «frente» a los casos en que existe una patología jurídica.

$\mathrm{Y}$ al igual que la medicina desea hacer frente a la patología médica, el Derecho Procesal hace «frente» a la patología jurídica con el bisturí que han de manejar los denominados órganos jurisdiccionales que llevan a cabo la «función» de juzgar y se hacer ejecutar lo juzgado, según las exigencias constitucionales (artículo 117.3. de la Constitución española) con el fin de hacer «frente» a los casos en que existe una patología jurídica en el marco del logro de una convivencia en paz.

\section{EL “MÉTODO» RELATIVO A LA FINALIDAD QUE PERSIGUE EL DERECHO PROCESAL CON LA MIRADA PUESTA EN EL ÚNICO REFERENTE QUE LO LEGITIMARÍA COMO ES EL TEXTO CONSTITUCIONAL}

Y gracias a la susodicha lectura del texto constitucional español, deberíamos asumir, por imperativo constitucional, que el bisturí del que se sirve el Derecho Procesal para que la actividad denominada «función jurisdiccional» por la que unos «órganos» llamados «jurisdiccionales»-los juzgados y tribunales - llevan a cabo la «función» de juzgar y de hacer ejecutar lo juzgado según - siempre- exigencias constitucionales (artículo 117.3. de la Constitución española) para hacer «frente» a los casos en que existe una patología jurídica, confluye en la idea base según la cual el Derecho Procesal solo está «en disposición» de garantizar que se ha tramitado el proceso que surge del artículo 24.2. de la Constitución española con el que se garantizaría que, para hacer frente a la patología jurídica, «todos tienen derecho (...) a un proceso público $(. .$.$) con todas las garantías»$ -constitucionales y procesales-.

Porque las anteriores indicaciones comprometen el «asunto» o «método» de para qué sirve el Derecho Procesal con la mirada puesta en el único referente que lo legitimaría como es el texto constitucional español, no me rindo en cuestionar las múltiples peroratas, que con el afán de establecer «doctrina», se han venido gestando con increíble monotonía con el fin de justificar «argumentos de autoridad» en torno a la más que englobante (y, ya fatigante) quaestio disputata relativa a los dichosos - no por felices - «argumentos de autoridad» supuestamente justificadores del Derecho Procesal y que tienen aún toda la pinta de ir para largo.

No poca culpa de ello cabe achacar al laconismo constitucionalista que es posible atribuir a esos «argumentos de autoridad» supuestamente justificadores del Derecho Procesal, aunque - hay que reconocerlo- el Tribunal Constitucional español se afana, a golpe de sentencia (único recurso disponible) por explicitar la cuantiosa «sustancia constitucional» que pareciera atesorar el Derecho Procesal respecto al entendimiento de lo que añejamente se conoce como «lo que la justicia diga» y que no siempre suele propiciar la tranquilidad y el sosiego de esas personas a las que un tanto pedantemente se les denomina «justiciables».

Prometedora se anuncia, pues, la ubicación del denominado Derecho Procesal en el esquema constitucionalista ya que de él cabe extraer, como hace el Tribunal Constitucional español, una serie de exigencias básicas que ha de observar el razonamiento de la función 
jurisdiccional consistente en juzgar y hacer ejecutar lo juzgado según las exigencias constitucionales (artículo 117.3. de la Constitución española) que, tal y como aparece configurado en la actualidad, ha de acomodarse a lo que hoy se estima ha de ser una motivación constitucionalista del aludido razonamiento de la función jurisdiccional en orden a garantizar el derecho a la tutela judicial, la presunción de inocencia, la interdicción de la indefensión... y así sucesivamente.

$\mathrm{Y}$, sin embargo, la situación no parece haber mejorado notoriamente pues pese al empeño del mencionado Tribunal Constitucional español, de ningún modo han aumentado los «argumentos de autoridad» justificadores de esa cuantiosa «sustancia constitucional» que se dice - y digo yo - atesora el Derecho Procesal en orden a la intelección de «lo que la justicia diga» y que compromete el acierto del tercero - juez o magistrado - que ha de resolver la «contienda judicial» (en términos del artículo 248.1. de la Ley de Enjuiciamiento Civil; o, Código Procesal Civil español) ante él planteada.

En el recinto de ese debate parece que seguiremos atrapados, condenados a re-suscitar los argumentos consabidos, de no ser porque ha de comenzar a rodar - y conmigo al frentela tesis de lo impropio que es justificar el Derecho Procesal en el logro de la denominada «justicia» o «verdad» en el contexto del esquema constitucionalista que ha de observar el razonamiento de la función jurisdiccional consistente en juzgar y hacer ejecutar lo juzgado según las exigencias constitucionales (artículo 117.3. de la Constitución española).

Así que la afirmación consistente en que el Derecho Procesal ni garantiza el acierto o corrección jurídica de la fundamentación de la sentencia que con arreglo a su normativa se pronuncie o que, asimismo, tampoco garantiza el triunfo de las pretensiones de las partes que a su través actúan, me ha puesto al corriente de este — para mí- «instructivo» planteamiento que pugna con «fuentes de información» que poseen un indudable «aire de familia de siempre» y que aún perseveran en postular que el Derecho Procesal se justifica en el logro de la denominada «justicia» $\mathrm{o}$ «verdad».

Por lo mismo, el Derecho Procesal tendría una indudable «vocación garantista» que gira en torno a la consecución de un «proceso justo» como el que surge del artículo 24.2. de la Constitución española y con el que se garantizaría que, para hacer frente a la patología jurídica, «todos tienen derecho (...) a un proceso público (...) con todas las garantías» - constitucionales y procesales - a través del estudio del ejercicio de la denominada «función jurisdiccional» consistente en juzgar y hacer ejecutar lo juzgado, según esas mismas exigencias constitucionales (artículo 117.3. de la Constitución española) por los órganos jurisdiccionales - juzgados y tribunales-.

\section{LA «RESPONSABILIDAD» DEL DERECHO PROCESAL}

No daría abasto si empezara a enumerar los logros de este révirement que la Constitución española ha propiciado para el Derecho Procesal español. Así que como creo que los márgenes de discusión a los que pudiera dar lugar lo indicado renglones antes no son precisamente menguados, desde ya me alistaré en la tropa de los críticos y comenzaré por aclarar - siempre es bueno saber en dónde se está, sobre todo si estas sumarias indicaciones acaban en las manos de un profesional del Derecho- que el denominado órganojurisdiccional — juzgado y tribunal-, que ejerce la función jurisdiccional consistente en juzgar y hacer ejecutar lo juzgado según las exigencias constitucionales (artículo 117.3. de la Constitución española), no garantizaría ni la corrección jurídica de la interpretación de las normas jurídicas, que lleve a cabo mediante el ejercicio de la denominada función jurisdiccional, al no existir un derecho al acierto de esos mismos órganos jurisdiccionales ni tampoco aseguraría la satisfacción de la pretensión de ninguna de las partes frente la patología jurídica planteada ante esos mismos órganos jurisdiccionales.

El Derecho Procesal, al que solo le justifica la norma constitucional y la función - la «función jurisdiccional» constitucional- que le acredita, no posee «resortes» $\mathrm{o}$ «instrumentos» para que la aplicación de la norma jurídica por los órganos jurisdiccionales en los casos de patología jurídica sea la correcta o para justificar el derecho al acierto de esos mismos órganos jurisdiccionales.

Y en conexión con lo recién apuntado, emerge un compte-rendu de lo acaecido en el Tribunal Constitucional español que, de forma 
reiterada, realiza una «dación de cuenta» de la hermenéutica acaecida en su seno. En efecto, asomados al balcón de las ponencias - y de sus ponentes - observamos — mejor, leemoscomo el ponente García-Mon y GonzálezRegueral (1994) dice que «el artículo 24.1 CE (de la Constitución española) no garantiza el acierto del órgano jurisdiccional en cuanto a la solución del caso concreto» (p. 125) o que el ponente Garrido, F. (2000) diga que el derecho a la tutela judicial efectiva no garantice «ni el acierto o corrección jurídica de la fundamentación, ni el triunfo de las pretensiones de las partes» (p. 272) o que, el ponente Jiménez (2001), reitere que «es obligado partir de una afirmación: el derecho a la tutela judicial efectiva no comprende un pretendido derecho al acierto judicial en la selección, interpretación y aplicación de las disposiciones legales») (p. 330) o, en fin, que el ponente Cruz Villalón (2001) vuelva a reiterar que «que el artículo 24.1 CE (de la Constitución española) no garantiza el acierto del órgano judicial en cuanto a la solución del caso concreto» (p. 400).

Es decir, el Derecho Procesal no se responsabiliza del «modo» en el que los denominados órganos jurisdiccionales —en el ejercicio de la «función jurisdiccional» constitucional de juzgar y hacer ejecutar lo juzgado según las exigencias constitucionales (artículo 117.3. de la Constitución española)_ aplican el "derecho» del denominado "estado de derecho» al no garantizar ni la corrección jurídica en la interpretación de las normas jurídicas que lleven a cabo al no existir un derecho al acierto de esos mismos órganos jurisdiccionales ni tampoco al no asegurar la satisfacción de las pretensiones de ninguna de las partes planteada ante esos mismos órganos jurisdiccionales.

El Derecho Procesal $-y$ es aquí a donde quería llegar - solo estaría en «disposición» de garantizar un «proceso justo» como el que se obtiene del artículo 24.2. de la Constitución española y con el que se garantizaría que, para hacer frente a la patología jurídica, «todos tienen derecho (...) a un proceso público (...) con todas las garantías" - constitucionales y procesales - a través del estudio del ejercicio de la denominada "función jurisdiccional» consistente en juzgar y se hacer ejecutar lo juzgado, según -reitero- las exigencias constitucionales (artículo 117.3. de la Constitución española).

\section{EL COMPROMISO CONSTITUCIONAL DEL DERECHO PROCESAL}

Ahora bien, puesto que el objeto de mi escrito consiste en contrastar ideas y no en buscar la confrontación (dialéctica, claro) con personas, me tomaré la licencia de confeccionar un constructo de la finalidad que persigue el Derecho Procesal que no sea el «retrato» de nadie. Y a «ese» nadie se le ocultara que, con esas reservas, ya estoy anticipando mi personal enmienda a la totalidad de los argumentos que, de consuno han servido para justificarlo por lo que, sin más demora, pasaré a exponerla. A ello voy.

Entre los que de buena gana aceptan (más que soportan) que en el denominado ya sin duda, añejamente- Derecho Procesal suele cultivarse la idea de que su cometido o finalidad es la de regular el proceso — de la función jurisdiccional consistente en juzgar y hacer ejecutar lo juzgado- (artículo 117.3. de la Constitución española), consienten -y, yo el primero - las insospechadas fecundidades provenientes de la aplicación al mismo — a la normativa del Derecho Procesal, se entiendede un sistema de garantías procesales que posibilita la rotunda aplicación por los miembros del Poder Judicial de la tutela judicial efectiva en los supuestos en que exista una patología jurídica.

No en vano, los Juzgados y Tribunales han de aplicar el proceso — de la función jurisdiccional consistente en juzgar y hacer ejecutar lo juzgado- (artículo 117.3. de la Constitución española) «con todas las garantías» (artículo 24.2. de la Constitución española) o «en garantía de cualquier derecho» (artículo 2.2. de la ley - española — orgánica del Poder Judicial). O sea, en sintonía con el reconocimiento, sin ambages, de la existencia de un garantismo en el Derecho Procesal - y, en consonancia con ello, de la «doctrina garantista» como sustrato teórico de la constitucionalización del proceso en franca expansión-.

Por lo mismo, no es posible que exista un planteamiento inicial tremendista cuando se indica que las exigencias constitucionales del ejercicio funcional de la jurisdicción por los miembros del Poder Judicial, se hallan particularmente garantizadas en su aplicación en nuestra Constitución - la española- (garantismo constitucional), a través de la existencia misma 
del proceso — de la función jurisdiccionalen orden a juzgar y hacer ejecutar lo juzgado (artículo 117.3. de la Constitución española) por juzgados y tribunales.

En tal sentido, el proceso - de la función jurisdiccional-, de cuyo estudio se ocupa el Derecho Procesal, es compromiso constitucional porque la Constitución española garantiza que el proceso pueda ser garantía de amparo de los derechos de todos los ciudadanos en los supuestos en que exista una patología jurídica.

\section{LA SUSTANTIVIDAD DEL DERECHO PROCESAL}

$\mathrm{Y}$, entonces, se da por definitivamente ganado que cuando el Derecho Procesal regula el proceso - de la función jurisdiccional consistente en juzgar y hacer ejecutar lo juzgado- (artículo 117.3. de la Constitución española) mediante la aplicación de un sistema de garantías procesales que posibilita la rotunda aplicación por los miembros del Poder Judicial del artículo $24 .^{\circ}$ de la Constitución española en orden a lograr la tutela judicial efectiva en los supuestos en que exista una patología jurídica, se está primando el sistema de garantías procesales a él aplicable —al Derecho Procesal, se entiende - , no siendo afortunado señalar que el Derecho Procesal contempla, fundamentalmente la aplicación — vertiente instrumental propia de un subsistema - a través de su normativa específica, del ordenamiento jurídico ya sea civil, laboral, penal, o en fin, contencioso administrativo.

Para que se me entienda. El Derecho Procesal no es un subsistema instrumental. Es el sistema de garantías procesales que actúa con autonomía y sustantividad propias.

No se trata de un artificio alambicado. Si se contempla el Derecho Procesal desde una vertiente exclusivamente instrumental, lo cierto es que se antepondría en su aplicación la actuación del ordenamiento jurídico ya sea civil, laboral, penal, o en fin, contencioso administrativo, pasando a un lugar secundario su más importante y primario contenido sustantivo como ordenamiento jurídico procesal, consistente en hacer posible el proceso - de la función jurisdiccional- a través de un sistema de garantías procesales que permitan, en todo momento e hipótesis, la tutela judicial efectiva (artículo $24 .^{\circ}$ de la Constitución española).

Y no suscita perplejidad alguna ubicar ese garantismo procesal en un Derecho Procesal en el que es posible conceptuar el proceso - de la función jurisdiccional - como una realidad sustantiva $-\mathrm{y}$, por ello, no instrumental- a través de una postura garantista plenamente comprometida con la realidad constitucional de «aquí y ahora».

\section{EL "CONCEPTO DE JUSTICIA" QUE PROPUGNA EL DERECHO PROCESAL}

Habría que indagar, entonces, si, cuando el artículo 24.2. de la Constitución española dispone que «todos tienen derecho [...] a un proceso público $[. .$.$] con todas las garantías»$ o cuando el artículo 2.2. de la Ley española - Orgánica del Poder Judicial indica que los órganos jurisdiccionales — juzgados $\mathrm{y}$ tribunales - ejercen funcionalmente - es decir, mediante el proceso- la jurisdicción «en garantía de cualquier derecho» o, en fin, cuando la exposición de motivos de la vigente Ley de Enjuiciamiento Civil - o, Código Procesal Civil español - de 2000 proclama y aclama que «justicia civil efectiva significa, por consustancial al concepto de Justicia, plenitud de garantías procesales», nos ubicamos ante un «acontecimiento inédito» en la más reciente historia del procesalismo español en el que, bregar con el anhelo de una justicia efectiva vinculada inexorablemente con el deseo de plenitud de garantías procesales, supondría, solo de entrada, decantarse por una opción no meramente instrumental sino efectiva de tutela judicial y que, además, supondría la confluencia de la tutela judicial efectiva, propia del civil law, con la del debido proceso de ley (due process of law), propio del common law por cuanto la «deuda» que se contrae en la aplicación según «ley» de las garantías procesales —debido=deuda contraida en la aplicación de las garantías procesales según la «ley» (due process of law) - supone para el civil law que «justicia civil efectiva» signifique según el artículo 24.2. de la Constitución española que «todos tienen derecho [...] a un proceso público $[\ldots]$ con todas las garantías».

Entonces, damos con un hallazgo; a saber que el "concepto de justicia» converge constitucionalmente, solo y exclusivamente, 
en un proceso que asuma la plenitud de garantías procesales y que, por tanto, «ese» proceso con plenitud de garantías procesales sería el denominado proceso justo. O lo que es lo mismo: todos tenemos derecho a un proceso justo con todas las garantías procesales. Y que, por lo mismo el concepto de «justicia» en Derecho Procesal confluiría en el la existencia de un proceso justo.

\section{LA «JUSTICIA O VERDAD»QUE GARANTIZA EL DERECHO PROCESAL}

No es ocioso afirmar, entonces, que el proceso justo sería el resultado de un debido proceso de ley (due process of law), propio del common law en razón de la «deuda» que se contrae en la aplicación según "ley» de las garantías procesales, o de la existencia de una «justicia civil efectiva» - a que alude el artículo 24.1. de la Constitución española- . Es decir, que el denominado «concepto de justicia» que administran los órganos jurisdiccionales - o sea los juzgados y tribunales integrantes del Poder Judicial español- confluiría en el proceso justo con plenitud de garantías procesales fruto de la «deuda» que se contrae en la aplicación según «ley»-constitucional y ordinaria - de las garantías procesales debido proceso de ley (due process of law) del derecho anglosajón-. O sea, que la única "justicia o verdad" que garantiza el Derecho Procesal es la de un proceso justo.

Por tanto, al Derecho Procesal le interesaría que los órganos jurisdiccionales —es decir, los juzgados y tribunales — actúen el proceso justo. Y que, consecuentemente, los órganos jurisdiccionales $-\mathrm{o}$ sea, los juzgados $\mathrm{y}$ tribunales- no asegurarían ni «justicia», ni «verdad» alguna. Recreémonos en la redundancia: los órganos jurisdiccionales — es decir, los juzgados y tribunales — solo garantizarían que, mediante el ejercicio de la función jurisdiccional, se tramite un proceso justo. Pero, no más.

Todo lo cual se traduce en que las garantías procesales previstas en el artículo $24 .^{\circ}$ de la Constitución española no garantizarían la corrección jurídica en la interpretación de las normas jurídicas llevada a cabo por los órganos jurisdiccionales —es decir, los Juzgados y Tribunales - pues no existe un derecho al acierto $\mathrm{y}$, tampoco, asegurarían la satisfacción de la pretensión de ninguna de las partes planteada ante ellos. En ningún caso queda comprometido el acierto del tercero - juez o magistrado- que ha de resolver la «contienda» (artículo 248.1. de la ley de enjuiciamiento civil; o, código procesal civil español) ante él planteada.

Lo que estoy diciendo es bien simple. El Derecho Procesal no posee «resortes» o «instrumentos» para que la aplicación de la norma jurídica por los órganos jurisdiccionales — juzgados y tribunales - en los casos de patología jurídica sea la correcta o para justificar el derecho al acierto de esos mismos órganos jurisdiccionales. Al respecto, el acierto del tercero - juez o magistrado - que ha de resolver la «contienda judicial» (artículo 248.1. de la Ley de Enjuiciamiento Civil; o, Código Procesal Civil español) ante él planteada no queda comprometido. Así que los órganos jurisdiccionales —es decir, los juzgados y tribunales - solo estarían «en disposición» de garantizar que se ha tramitado un proceso justo. Pero, nada más.

Es decir, que el denominado «concepto de justicia» que administran los órganos jurisdiccionales — los juzgados y tribunales integrantes del Poder Judicial españolconfluiría en el proceso justo con plenitud de garantías procesales fruto de la «deuda» que se contrae en la aplicación según «ley»constitucional y ordinaria - de las garantías procesales debido proceso de ley (due process of law) del derecho anglosajón- y que - ahora sí- comprometería o diseñaría el acierto del tercero — juez o magistradoque ha de resolver la «contienda judicial» (artículo 248.1. de la Ley de Enjuiciamiento Civil; o, Código Procesal Civil español) ante él planteada.

Inducido por estas ideas debo, entonces, alertar al lector en que aquello que esperas de la norma procesal no es el acierto. Es la «justicia» o la "verdad» de un proceso justo. Is the «justice» or «truth» of a fair process.

\section{CONCLUSIONES}

El Derecho Procesal tendría una indudable «vocación garantista» que gira en torno a la consecución de un «proceso justo» como el que surge del artículo 24.2. de la Constitución española y con el que se garantizaría que, para 
hacer frente a la patología jurídica, «todos tienen derecho $[\ldots]$ a un proceso público $[\ldots]$ con todas las garantías» - constitucionales y procesales - a través del estudio del ejercicio de la denominada "función jurisdiccional» consistente en juzgar y hacer ejecutar lo juzgado, según esas mismas exigencias constitucionales.

Al Derecho Procesal le interesaría que los órganos jurisdiccionales -es decir, los juzgados y tribunales - actúen el proceso justo. Y que, consecuentemente, los órganos jurisdiccionales - es decir, los juzgados y tribunales - no asegurarían ni «justicia», ni «verdad» alguna.

El Derecho Procesal no posee «resortes» o «instrumentos» para que la aplicación de la norma jurídica por los órganos jurisdiccionales - juzgados y tribunales - en los casos de patología jurídica sea la correcta o para justificar el derecho al acierto de esos mismos órganos jurisdiccionales.

\section{REFERENCIAS BIBLIOGRÁFICAS}

Cruz Villalón.(2001). Boletín dejurisprudencia constitucional 243.

García-Mon y González-Regueral, F. (1994)

Boletín de jurisprudencia constitucional 157.

Garrido Falla. (2000). Boletín de jurisprudencia constitucional 230.

Jiménez Sánchez. (2001). Boletín de jurisprudencia constitucional 243.

Vallespín, D. (2002). “El modelo constitucional de juicio justo en el ámbito del proceso civil: conexión entre el derecho a la tutela judicial efectiva y el derecho a un proceso con todas las garantías". Barcelona: Atelier. 